\title{
THE PHYSICOCHEMICAL PROPERTIES AND ANTIOXIDANT CAPACITIES OF COMMERCIAL AND HOMEMADE GREEK VINEGARS
}

\author{
Olga S. Arvaniti, Panagiotis Mitsonis, loannis Siorokos, Endrysa Dermishaj, \\ Yiannis Samaras ${ }^{\bowtie}$ \\ Department of Food Science and Technology, Laboratory of Wine and Spirits' Quality Control, Ionian University \\ Vergoti's Av., Argostoli, 28100 Kefalonia, Greece
}

\begin{abstract}
Background. Due to its high content of antioxidant compounds, vinegar can be considered an excellent source of health promoting compounds. The aim of this study was to compare the physicochemical composition and antioxidant capacity of eighteen vinegars made from red and white wine, apple, rose petals, and balsamic acid.

Materials and methods. Eight randomly selected commercial vinegars from the Greek market and ten homemade vinegars were used. Their quality characteristics, color profile, polyphenol content and antioxidant capacity were determined.

Results. The results showed that there is a high diversity of values among the examined vinegar samples indicating that the raw material and the applied production methods can affect their composition. Red wine vinegars and red balsamic vinegars exhibited the highest levels of total phenols, followed by fruit vinegars, white wine vinegars and white balsamic vinegars. The antioxidant capacity was strongly affected by the total phenolic content, followed by the total flavonoid content and less so by the color density.

Conclusion. Our findings could provide important information to consumers about the randomly selected vinegars from the Greek market and could be used for the development and optimization of homemade and commercial vinegars.
\end{abstract}

Keywords: vinegar, polyphenols, antioxidant activity, color, quality control, spectrophotometric methods

\section{INTRODUCTION}

Vinegar is an acidic liquid product that has been used worldwide as seasoning in salads, sauces and cooking, as a medicine and as an anti-aging product (Budak et al., 2014; Ho et al., 2017). The two main methods of vinegar production are alcoholic fermentation (conversion of sugar to alcohol) and acetous fermentation (conversion of alcohol to acetic acid) (Budak et al. 2014; Ho et al., 2017). There are many types of vinegar worldwide; based on the raw materials used, they are classified into the following categories: wine vinegar (red or white), fruit vinegar, rice vinegar, balsamic vinegar, malt vinegar and beer vinegar (Ho et al., 2017). Vinegar is considered to be a healthy and functional food due to its high content of natural antioxidant compounds, including phenolic compounds, vitamins $\mathrm{C}$ and $\mathrm{E}$, micronutrients, minerals 
and organic acids (Ho et al., 2017). It is well known that the consumption of food rich in these compounds can reduce the risk of chronic diseases like cardiovascular diseases, cataracts, diabetes, neurodegenerative illnesses, and cancer (Arvaniti et al., 2019). The therapeutic properties of vinegar, such as antibacterial activity, blood pressure reduction, antioxidant activity, reduction in the effects of diabetes and prevention of cardiovascular disease have been reported after exercise (Budak et al., 2014; Ho et al., 2017; Ozturk et al., 2015).

In a few recent studies, spectrophotometric and chromatographic techniques have been used to investigate the bioactive compounds, volatile composition and antioxidant capacity of different types of vinegar (Barnaba et al., 2015; Budak et al., 2010; Cruz et al., 2018; Kelebek et al., 2017; Ubeda et al., 2011; Yu et al., 2012). However, little data has been published so far, while a characterization of vinegars in the Greek market has not been extensively studied (Lalou et al., 2015; Sinanoglou et al., 2018) and a comparison of them with homemade vinegars has not been conducted. The main organic acid in vinegar is acetic acid, from which the unique flavor and aroma of vinegar originate, while tartaric acid, formic acid, lactic acid, citric acid, malic acid and succinic acid have also been detected (Aguiar et al., 2005; Sanarico et al., 2003). Previous studies have reported that there are several factors that can affect the physicochemical content and antioxidant activity of vinegar, such as the fermentation process, raw materials, storage conditions and aging period (Budak et al., 2010; Cruz et al., 2018; Ho et al., 2017; Xia et al., 2018).

The aims of the current research were to investigate the physicochemical properties, antioxidant capacities and color profiles of homemade vinegars against randomly selected commercial vinegars from the Greek market and to examine the role of raw materials on their characteristics. For this reason, eight (8) commercial and ten (10) homemade vinegars were collected; namely three balsamic vinegars, one commercial red wine vinegar (RWCV), one commercial white wine vinegar (WWCV), nine homemade red wine vinegars (RWHVs), one homemade white wine vinegar (WWHV) and three commercial fruit vinegars (FVs) with apple and rose petals.

\section{MATERIALS AND METHODS}

\section{Chemicals and reagents}

Gallic acid, Folin-Ciocalteu reagent, potassium persulfate, sodium nitrite and aluminium chloride were supplied by Merck (Darmstadt, Germany). Ascorbic acid, trolox (6-hydroxy-2,5,7,8-tetramethylchroman-2-carboxylic acid), DPPH (2,2-diphenyl-1-picrylhydrazyl) and sodium hydroxide were obtained from Sigma-Aldrich (St. Louis, USA). Quercetin was purchased from Alfa Aesar (Karlsruhe, Germany), whereas sodium carbonate was supplied by Riedel-de Haën (Seelze, Germany). The ABTS reagent [2,2'-Azinobis(3-ethylbenzothiazoline-6-sulfonic acidammoniumsalt)] was obtained from TCI Chemicals (Gurgaon, India). The sulfuric acid solution, iodine solution, thiosulfate solution, and standard stock solutions of organic acids and sugars were purchased from Technologia Difusión Ibéria (Barcelona, Spain). Distilled water was provided by a CFL Water Distillation Unit (Dublin, Ireland). All chemicals and solvents were analytical grade ( $>99 \%)$.

\section{Vinegar samples}

Eighteen vinegars, some originating from the Greek market and others homemade, were collected in this study. Detailed information of all the examined vinegars is listed in Table 1. All samples were stored at room temperature in the dark and analyzed immediately after opening.

\section{Determination of quality characteristics}

$\mathrm{pH}$, alcohol content, density and acidity of the eighteen tested vinegar samples were determined using a Fourier-transform infrared spectroscopy (FTIR) wine analyzer (Thermo Scientific Nicolet iS5). A TDI Miura One chemical analyzer was employed to quantify organic acids, such as citric acid and tartaric acid, and sugars, such as reducing sugars and non-reducing sugars. Turbidity was measured using a Lovibond infrared turbidity meter (TB 210 IR) by Tintometer (Amesbury, England), while free and total sulphur oxide contents were determined using a TDI ENO 20 wine analyzer by Tecnología Difusión Ibérica (Barcelona, Spain). 
Arvaniti, O. S., Mitsonis, P., Siorokos, I., Dermishaj, E., Samaras, Y. (2019). The physicochemical properties and antioxidant capacities of commercial and homemade Greek vinegars. Acta Sci. Pol. Technol. Aliment., 18(3), 225-234. http://dx.doi.org/10.17306/ J.AFS.2019.0669

Table 1. Description of samples and quality parameters of examined vinegar samples

\begin{tabular}{|c|c|c|c|c|c|c|c|c|c|}
\hline \multicolumn{10}{|c|}{ Commercial } \\
\hline type & brand name & $\begin{array}{c}\text { alcohol } \\
\%\end{array}$ & $\mathrm{pH}$ & $\begin{array}{l}\text { density } \\
\mathrm{g} \mathrm{L}^{-1}\end{array}$ & $\begin{array}{c}\text { turbitity } \\
\text { NTU }\end{array}$ & $\begin{array}{l}\text { total acidity } \\
\mathrm{g} / 100 \mathrm{~mL}\end{array}$ & $\begin{array}{l}\text { volatile } \\
\text { acidity } \\
\mathrm{g} / 100 \mathrm{~mL}\end{array}$ & $\begin{array}{c}\text { free } \mathrm{SO}_{2} \\
\mathrm{mg} \mathrm{L}^{-1}\end{array}$ & $\begin{array}{c}\text { total } \mathrm{SO}_{2} \\
\mathrm{mg} \mathrm{L}^{-1}\end{array}$ \\
\hline \multicolumn{10}{|c|}{ Balsamic vinegar } \\
\hline Red balsamic ${ }^{\mathrm{a}, \mathrm{b}}$ & Hartouliaris & 2.46 & 2.79 & 1.10 & 1.74 & 3.3 & 1.9 & 2 & 3 \\
\hline $\begin{array}{l}\text { Red balsamic } \\
\text { with pomegranate }\end{array}$ & Pan & 0.85 & 2.85 & 1.01 & 8.41 & 6.1 & 4.0 & 7 & 12 \\
\hline White balsamic & Top - Minerva & 0.54 & 2.84 & 1.15 & 26.1 & 5.0 & 2.4 & 2 & 2 \\
\hline \multicolumn{10}{|c|}{ Commercial red wine vinegar: RWCV } \\
\hline RWCV & Top - Minerva & 0.85 & 2.89 & 1.01 & 0.79 & 6.1 & 4.0 & 17 & 25 \\
\hline \multicolumn{10}{|c|}{ Commercial white wine vinegar: WWCV } \\
\hline WWCV & Alta - Metro S.A. & 0.57 & 2.43 & 1.01 & 1.12 & 5.1 & 3.5 & 32 & 36 \\
\hline \multicolumn{10}{|c|}{ Fruit vinegar: FV } \\
\hline FV Apple 1 & Alta - Metro S.A & 0.59 & 2.44 & 1.01 & 1.14 & 5.1 & 3.5 & 81 & 83 \\
\hline FV Apple 2 & $\begin{array}{l}\text { Paros }- \text { K. Sifnaios } \\
\& \mathrm{CO}\end{array}$ & 0.75 & 2.61 & 1.01 & 2.05 & 5.3 & 3.4 & 50 & 52 \\
\hline FV Rose petals ${ }^{\mathrm{a}, \mathrm{b}}$ & Hartouliaris & 2.18 & 2.76 & 1.01 & 15.3 & 5.7 & 3.7 & 1 & 2 \\
\hline \multicolumn{10}{|c|}{ Homemade } \\
\hline type & grape variety & $\begin{array}{c}\text { alcohol } \\
\%\end{array}$ & $\mathrm{pH}$ & $\begin{array}{l}\text { density } \\
\mathrm{g} \mathrm{L}^{-1}\end{array}$ & $\begin{array}{c}\text { turbitity } \\
\text { NTU }\end{array}$ & $\begin{array}{l}\text { total acidity } \\
\mathrm{g} / 100 \mathrm{~mL}\end{array}$ & $\begin{array}{l}\text { volatile } \\
\text { acidity } \\
\mathrm{g} / 100 \mathrm{~mL}\end{array}$ & $\begin{array}{l}\text { free } \mathrm{SO}_{2} \\
\mathrm{mg} \mathrm{L}^{-1}\end{array}$ & $\begin{array}{l}\text { total } \mathrm{SO}_{2} \\
\mathrm{mg} \mathrm{L}^{-1}\end{array}$ \\
\hline \multicolumn{10}{|c|}{ Homemade red wine vinegar: RWHV } \\
\hline RWHV $1^{\mathrm{a}}$ & $\begin{array}{l}\text { Tsaousi } \\
\text { Vostilidi } \\
\text { Robola } \\
\text { Mavrodafni }\end{array}$ & 4.32 & 2.87 & 1.01 & 18.4 & 4.2 & 2.7 & 2 & 5 \\
\hline RWHV $2^{a, c}$ & $\begin{array}{l}\text { Assyrtiko } 30 \% \\
\text { Merlot } 50 \% \\
\text { Roditis } 20 \%\end{array}$ & 2.98 & 2.92 & 1.01 & 31.8 & 6.1 & 4.0 & 1 & 3 \\
\hline RWHV $3^{a, b}$ & $\begin{array}{l}\text { Mavrodafni } 25 \% \\
\text { Roditis } 75 \%\end{array}$ & 1.25 & 2.89 & 1.02 & 7.15 & 7.5 & 5.0 & 1 & 5 \\
\hline RWHV 4 & Roditis $80 \%$ & 1.22 & 2.88 & 1.02 & 3.33 & 7.5 & 5.1 & 1 & 1 \\
\hline RWHV 5 & Roditis $80 \%$ & 6.44 & 3.20 & 1.00 & 91.3 & 3.8 & 2.6 & 1 & 5 \\
\hline RWHV 6 & Mavrodafni $100 \%$ & 2.27 & 3.00 & 1.02 & 178 & 7.6 & 5.1 & 1 & 1 \\
\hline RWHV 7 & $\begin{array}{l}\text { Tsaousi } 45 \% \\
\text { Vostilidi } 45 \% \\
\text { Moscato } 10 \%\end{array}$ & 10.9 & 2.78 & 0.99 & 63.4 & 1.6 & 0.9 & 2 & 4 \\
\hline RWHV 8 & $\begin{array}{l}\text { Tsaousi } 50 \% \\
\text { Vostilidi 50\% }\end{array}$ & 7.72 & 3.39 & 1.00 & 33.0 & 3.9 & 2.6 & 2 & 3 \\
\hline RWHV 9 & Mavrodafni $100 \%$ & 3.72 & 3.02 & 1.02 & 6.86 & 4.9 & 3.2 & 1 & 3 \\
\hline \multicolumn{10}{|c|}{ Homemade white wine vinegar: WWHV } \\
\hline WWHV & $\begin{array}{l}\text { Assyrtiko } 80 \% \\
\text { Moscato } 20 \%\end{array}$ & 3.48 & 2.69 & 1.01 & 1.95 & 6.6 & 4.3 & 1 & 1 \\
\hline
\end{tabular}

$\mathrm{a}$ - aged with oak wood barrels, $\mathrm{b}$ - aged $4-5$ years, $\mathrm{c}$ - aged more than 10 years. 


\section{Vinegar color analysis}

The CIE $L^{*} a^{*} b^{*}$ color space was obtained using a Lovibond PFXi-195 Series colorimeter (Tintometer Ltd., UK). The following color coordinates were obtained: lightness $\left(L^{*}\right)$, red-green $\left(a^{*}\right)$ and yellow-blue $\left(b^{*}\right)$. The color density $(\mathrm{CD})$ and color tint $(\mathrm{CT})$ of vinegars were calculated by measuring the absorbance spectrophotometrically at $420 \mathrm{~nm}, 520 \mathrm{~nm}$ and $620 \mathrm{~nm}$ with a double-beam UV-Vis spectrophotometer (Unicam Helios) according to Eqs 1 and 2.

$$
\begin{gathered}
\mathrm{CD}=\mathrm{A}_{420}+\mathrm{A}_{520}+\mathrm{A}_{620} \\
\mathrm{CT}=\mathrm{A}_{420} / \mathrm{A}_{520}
\end{gathered}
$$

\section{Total phenolic content}

The amount of total phenolics in each sample was measured based on a previously published Folin-Ciocalteu assay (Arnous et al., 2001), using micro volumes of reagents and samples. Absorption was measured at $750 \mathrm{~nm}$ with a Unicam Helios UV-Vis spectrophotometer and the results expressed as $\mathrm{mg}$ of gallic acid equivalents (GAE) per L. A calibration curve of GAE was constructed in the $50-1000 \mathrm{mg} \mathrm{L}^{-1}$ concentration range.

\section{Total flavonoid content}

The level of total flavonoids in the examined vinegars was measured according to published work by Zhishen et al. (1999). Absorption was read at $510 \mathrm{~nm}$ using a Unicam Helios UV-Vis spectrophotometer and the results were expressed as $\mathrm{mg}$ of quercetin equivalents $(\mathrm{QE})$ per L. Standard solutions of quercetin were prepared at five concentration levels ranging from 50 to $500 \mathrm{mg} \mathrm{L}^{-1}$.

\section{DPPH assay}

The free radical scavenging activity of vinegars was determined according to the published method of Brand-Williams et al. (1995). The absorbance was taken at $492 \mathrm{~nm}$ using an Elisa plate reader (TECAN Sunrise) and the absorbance of the remaining DPPH was recorded. Standard solutions of ascorbic acid (AsA) were prepared at different concentration levels ranging from 0.1 to $1.2 \mathrm{mM}$ and a calibration curve based on the percentage inhibition of the DPPH radical scavenging activity of known concentrations of AsA was constructed. The results were expressed as $\mathrm{mM}\left(\mathrm{mmol} \mathrm{L}^{-1}\right)$ AsA.

\section{ABTS assay}

The antioxidant capacity of vinegar samples in the reaction with a stable ABTS radical cation (ABTS $\bullet^{+}$) was determined based on a previously published method by Re et al. (1999). Absorbance was measured at $734 \mathrm{~nm}$ using a Unicam Helios UV-Vis spectrophotometer. Results were expressed as $\mathrm{mM}\left(\mathrm{mmol} \mathrm{L}^{-1}\right)$ trolox equivalent (TE).

\section{Statistical analysis}

Determination of the polyphenol profile and antioxidant capacity was performed in three replicates and the measurements were expressed as an average \pm standard deviation (S.D.). The significance of the differences between groups was checked by one-way ANOVA at a significance level of 0.05 . In addition, correlation analysis between antioxidant capacity, polyphenol content and color parameters was performed using Microsoft Excel through the CORREL function.

\section{RESULTS AND DISCUSSION}

When comparing the quality characteristics and chemical composition of the examined vinegars, a great diversity was observed in the obtained values. It is well known that various factors such as production methods, raw materials (grape, apple, pomegranate, rose petals), storage conditions, wood contact and aging period can affect the physicochemical composition and sensory properties of vinegars and contribute to the final quality of vinegars (Budak et al., 2010; Cruz et al., 2018; Ho et al., 2017; Xia et al., 2018). In Table 1 , the physicochemical properties of 18 different examined vinegar samples are presented, while their organic acid and sugar contents are summarized in Table S1. The high levels of alcohol observed in some of the samples (Table 1) appear possible due to the fact that the acetic fermentation may have stopped or incomplete. The reason why fermentation might not have been completed is the high concentration of alcohol initially in the wines, a situation mainly observed in the homemade samples. Many times, producers of homemade vinegar don't dilute the wine with water and, as a result, the vinegar process stops because Sacharomycetes cannot tolerate high levels of alcohol and the level of alcohol remains high until the end of the process. $\mathrm{pH}$ values of the samples 
Arvaniti, O. S., Mitsonis, P., Siorokos, I., Dermishaj, E., Samaras, Y. (2019). The physicochemical properties and antioxidant capacities of commercial and homemade Greek vinegars. Acta Sci. Pol. Technol. Aliment., 18(3), 225-234. http://dx.doi.org/10.17306/ J.AFS.2019.0669

Table S1. Content of sugars and organic acids of examined samples

\begin{tabular}{|c|c|c|c|c|}
\hline \multirow{2}{*}{ Type } & \multicolumn{2}{|c|}{ Sugars, $\mathrm{g} \mathrm{L}^{-1}$} & \multicolumn{2}{|c|}{ Organic acids, $\mathrm{g} \mathrm{L}^{-1}$} \\
\hline & reducing sugars & non-reducing sugars & citric acid & tartaric acid \\
\hline \multicolumn{5}{|c|}{ Balsamic vinegar } \\
\hline Red balsamic & 12.34 & 80.2 & 0.06 & 1.94 \\
\hline $\begin{array}{l}\text { Red balsamic } \\
\text { with pomegranate }\end{array}$ & 16.09 & 313.9 & n.d. & 0.20 \\
\hline White balsamic & 15.57 & 304.6 & n.d. & 0.20 \\
\hline \multicolumn{5}{|c|}{ Commercial red wine vinegar: RWCV } \\
\hline RWCV & 0.59 & 13.1 & n.d. & 0.26 \\
\hline \multicolumn{5}{|c|}{ Homemade red wine vinegar: RWHV } \\
\hline RWHV 1 & 1.91 & 5.9 & 0.02 & 2.98 \\
\hline RWHV 2 & 0.64 & 3.5 & 0.01 & 1.70 \\
\hline RWHV 3 & 0.17 & 3.9 & n.d. & 1.50 \\
\hline RWHV 4 & 0.19 & 3.3 & n.d. & 1.50 \\
\hline RWHV 5 & 0.44 & 8.2 & n.d. & 1.80 \\
\hline RWHV 6 & 0.51 & 11.6 & n.d. & 1.50 \\
\hline RWHV 7 & 0.29 & 7.6 & n.d. & 1.85 \\
\hline RWHV 8 & 0.53 & 9.1 & n.d. & 1.91 \\
\hline RWHV 9 & 14.28 & 148.8 & n.d. & 3.52 \\
\hline \multicolumn{5}{|c|}{ Commercial white wine vinegar: WWCV } \\
\hline WWCV & n.d. & 4.7 & 0.02 & 0.24 \\
\hline \multicolumn{5}{|c|}{ Homemade white wine vinegar: WWHV } \\
\hline WWHV & 0.25 & 2.8 & 0.01 & 2.72 \\
\hline \multicolumn{5}{|c|}{ Fruit vinegar: FV } \\
\hline FV Apple 1 & n.d. & 0.3 & 0.01 & 0.20 \\
\hline FV Apple 2 & n.d. & 2.1 & 0.01 & 0.20 \\
\hline FV Rose petals & 2.85 & 7.8 & 0.02 & 2.85 \\
\hline
\end{tabular}

n.d. - not detected.

ranged between 2.43 (WWCV) and 3.39 (RWHV 8), while only two of the examined samples presented $\mathrm{pH}$ values $<2.5$. In general, these $\mathrm{pH}$ levels were similar to those reported in previous studies (Aguiar et al., 2005; Ozturk et al., 2015). A possible reason for the deviations observed in $\mathrm{pH}$ values among the examined samples could be their different organic acid contents. The obtained total acidity values showed a maximum acidity of $7.6 \mathrm{~g} / 100 \mathrm{~mL}$ (Table 1). It is important to note that the volatile acidity level is a function of the acetic fermentation. If there is any non-acidified alcohol, then the putative acidity has been decreased. On the other hand, the samples' density is a function of the content of sugar and alcohol. The density levels in all the tested samples are similar, apart from the red and white balsamic (Table 1). These two are made by using concentrated must. The highest turbidity values were observed in the homemade vinegar samples. 
More specifically, five out of a total of nine RWHV samples had a turbidity higher than 30 NTU. Regarding the total $\mathrm{SO}_{2}$ amount, with the exception of almost all the commercial vinegars, trace levels were detected. Lastly, the total sugars were higher in all examined balsamic vinegars and tartaric acid presented as the main organic acid in all samples (Table S1).

\section{Color evaluation}

One of the most important factors for vinegar is its color, as consumers have a preference for vinegars with a nice color. For this reason, it is crucial to produce vinegars with an attractive color and high nutritional value. The color parameters of the vinegar samples are given in Table S2. Results showed that all WWCV, WWHV, FV with apple and white balsamic vinegar exhibited negative $a^{*}$ values, indicated less red color and more green color, and $L^{*}$ values $>90.1$ demonstrated the high lightness of these samples. Lastly, the calculated low CD values (0.05-0.72) confirmed their weak chroma. On the other hand, RWCV, RWHVs, FV with rose petals and red balsamic vinegars exhibited

Table S2. Chromatic parameters of vinegar samples

\begin{tabular}{|c|c|c|c|c|c|}
\hline Type & $L^{*}$ & $\alpha^{*}$ & $b^{*}$ & $\mathrm{CD}$ & $\mathrm{CI}$ \\
\hline \multicolumn{6}{|c|}{ Balsamic vinegar } \\
\hline Red balsamic & 0.14 & 2.74 & 0.68 & 23.42 & 3.09 \\
\hline $\begin{array}{l}\text { Red Balsamic } \\
\text { with pomegranate }\end{array}$ & 52.1 & 54.3 & 43.2 & 3.32 & 1.04 \\
\hline White balsamic & 94.4 & -0.90 & 7.92 & 0.39 & 4.29 \\
\hline \multicolumn{6}{|c|}{ Commercial red wine vinegar: RWCV } \\
\hline RWCV & 80.4 & 10.6 & 34.6 & 1.12 & 2.38 \\
\hline \multicolumn{6}{|c|}{ Homemade red wine vinegar: RWHV } \\
\hline RWHV 1 & 69.5 & 22.7 & 21.7 & 1.49 & 1.56 \\
\hline RWHV 2 & 57.7 & 27.2 & 34.4 & 2.24 & 1.59 \\
\hline RWHV 3 & 84.7 & 2.68 & 30.8 & 0.73 & 3.18 \\
\hline RWHV 4 & 87.0 & 1.80 & 28.1 & 0.73 & 3.12 \\
\hline RWHV 5 & 77.5 & 3.12 & 37.8 & 1.15 & 3.63 \\
\hline RWHV 6 & 43.5 & 31.1 & 54.4 & 3.34 & 1.97 \\
\hline RWHV 7 & 81.4 & 1.28 & 28.7 & 0.89 & 4.38 \\
\hline RWHV 8 & 62.1 & 3.63 & 37.4 & 1.15 & 3.44 \\
\hline RWHV 9 & 85.3 & 1.84 & 28.6 & 0.93 & 3.94 \\
\hline \multicolumn{6}{|c|}{ Commercial white wine vinegar: WWCV } \\
\hline WWCV & 96.0 & -0.63 & 2.61 & 0.22 & 5.67 \\
\hline \multicolumn{6}{|c|}{ Homemade white wine vinegar: WWHV } \\
\hline WWHV & 90.1 & -0.97 & 17.3 & 0.72 & 4.67 \\
\hline \multicolumn{6}{|c|}{ Fruit vinegar: FV } \\
\hline FV Apple 1 & 91.6 & -0.53 & 3.57 & 0.05 & 5.40 \\
\hline FV Apple 2 & 94.6 & -1.21 & 10.7 & 0.28 & 4.40 \\
\hline FV Rose petals & 70.8 & 20.1 & 24.8 & 1.23 & 2.08 \\
\hline
\end{tabular}


Arvaniti, O. S., Mitsonis, P., Siorokos, I., Dermishaj, E., Samaras, Y. (2019). The physicochemical properties and antioxidant capacities of commercial and homemade Greek vinegars. Acta Sci. Pol. Technol. Aliment., 18(3), 225-234. http://dx.doi.org/10.17306/ J.AFS.2019.0669

high $a^{*}$ values and $L^{*}$ values between 0.14 and 87.0. The $\mathrm{CD}$ values were calculated in the range from 0.73 to 23.42 , thus confirming their dark color. In addition, for all samples CT values were estimated, which classified the color hue for each analyzed vinegar.

\section{Polyphenol content}

The total phenolic (TP) and total flavonoid (TF) content of vinegars were determined by spectrophotometric methods (Table 2). Vinegars made from red wine had the highest content followed by red balsamic vinegars

Table 2. Total phenolic content, total flavonoid content and values of antioxidant assays, DPPH and ABTS

\begin{tabular}{|c|c|c|c|c|}
\hline Type & $\begin{array}{l}\text { Total phenolic content } \\
\mathrm{mg} \mathrm{L}^{-1} \mathrm{GAE}^{1}\end{array}$ & $\begin{array}{l}\text { Total flavonoid content } \\
\mathrm{mg} \mathrm{L}^{-1} \mathrm{QE}^{2}\end{array}$ & $\begin{array}{l}\text { DPPH assay } \\
\text { mM AsA }^{3}\end{array}$ & $\begin{array}{l}\text { ABTS assay } \\
\mathrm{mM} \mathrm{TE}^{4}\end{array}$ \\
\hline \multicolumn{5}{|c|}{ Balsamic vinegar } \\
\hline Red balsamic & $650 \pm 42.4^{\mathrm{a}, \mathrm{b}, \mathrm{c}, \mathrm{d}, \mathrm{e}, \mathrm{f}, \mathrm{g}}$ & $2420 \pm 26.5^{\mathrm{a}, \mathrm{b}, \mathrm{c}, \mathrm{d}, \mathrm{e}, \mathrm{f}, \mathrm{g}}$ & $2.15 \pm 0.07^{\mathrm{a}, \mathrm{b}, \mathrm{d}, \mathrm{g}}$ & $1.30 \pm 0.05$ \\
\hline $\begin{array}{l}\text { Red balsamic } \\
\text { with pomegranate }\end{array}$ & $500 \pm 28.3^{\mathrm{b}, \mathrm{c}, \mathrm{d}, \mathrm{f}, \mathrm{g}}$ & $132 \pm 6.4^{\mathrm{a}, \mathrm{b}, \mathrm{d}, \mathrm{e}, \mathrm{g}}$ & $2.08 \pm 0.07^{\mathrm{b}, \mathrm{c}, \mathrm{d}, \mathrm{g}}$ & $0.98 \pm 0.02$ \\
\hline White balsamic & $169 \pm 3.1^{\mathrm{a}, \mathrm{c}, \mathrm{d}, \mathrm{e}, \mathrm{f}}$ & $51 \pm 4.5^{\mathrm{a}, \mathrm{c}, \mathrm{d}, \mathrm{e}, \mathrm{f}}$ & $0.27 \pm 0.04^{\mathrm{a}, \mathrm{c}, \mathrm{d}, \mathrm{e}, \mathrm{f}}$ & $0.07 \pm 0.01$ \\
\hline \multicolumn{5}{|c|}{ Commercial red wine vinegar: RWCV } \\
\hline RWCV & $360 \pm 31.0^{\mathrm{a}, \mathrm{b}, \mathrm{c}, \mathrm{d}}$ & $188 \pm 14.8^{\mathrm{e}}$ & $1.78 \pm 0.06^{\mathrm{b}, \mathrm{d}}$ & $1.07 \pm 0.04$ \\
\hline \multicolumn{5}{|c|}{ Homemade red wine vinegar: RWHV } \\
\hline RWHV 1 & $706 \pm 14.1$ & $1150 \pm 75.5$ & $2.39 \pm 0.03$ & $1.39 \pm 0.93$ \\
\hline RWHV 2 & $496 \pm 33.5$ & $1280 \pm 52.9$ & $2.54 \pm 0.05$ & $1.46 \pm 0.12$ \\
\hline RWHV 3 & $370 \pm 18.3$ & $181 \pm 16.5$ & $1.86 \pm 0.01$ & $1.05 \pm 0.06$ \\
\hline RWHV 4 & $374 \pm 19.8$ & $174 \pm 21.2$ & $1.74 \pm 0.19$ & $1.07 \pm 0.10$ \\
\hline RWHV 5 & $252 \pm 24.0$ & $137 \pm 12.7$ & $0.88 \pm 0.02$ & $0.28 \pm 0.003$ \\
\hline RWHV 6 & $249 \pm 28.4$ & $634 \pm 57.7$ & $1.34 \pm 0.01$ & $1.75 \pm 0.14$ \\
\hline RWHV 7 & $348 \pm 14.4$ & $237 \pm 12.9$ & $1.88 \pm 0.05$ & $1.27 \pm 0.06$ \\
\hline RWHV 8 & $539 \pm 24.4$ & $473 \pm 51.9$ & $2.52 \pm 0.07$ & $1.38 \pm 0.02$ \\
\hline RWHV 9 & $452 \pm 4.6$ & $223 \pm 22.5$ & $2.01 \pm 0.06$ & $1.28 \pm 0.14$ \\
\hline & $421 \pm 146^{b, c, d}$ & $499 \pm 419^{a, b . c, d}$ & $1.91 \pm 0.55^{a, b, c, d}$ & $1.21 \pm 0.41$ \\
\hline \multicolumn{5}{|c|}{ Commercial white wine vinegar: WWCV } \\
\hline WWCV & $113 \pm 4.6^{\mathrm{a}, \mathrm{c}}$ & $262 \pm 13.1^{\mathrm{b}, \mathrm{c}}$ & $0.19 \pm 0.03^{\mathrm{a}, \mathrm{b}, \mathrm{c}}$ & $0.04 \pm 0.02$ \\
\hline \multicolumn{5}{|c|}{ Homemade white wine vinegar: WWHV } \\
\hline WWHV & $233 \pm 9.2^{\mathrm{a}}$ & $138 \pm 14.0^{\mathrm{a}, \mathrm{d}}$ & $1.39 \pm 0.07^{\mathrm{a}, \mathrm{b}}$ & $1.15 \pm 0.07$ \\
\hline \multicolumn{5}{|c|}{ Fruit vinegar: FV } \\
\hline FV Apple 1 & $230 \pm 10.5$ & $43 \pm 1.2$ & $0.26 \pm 0.006$ & $0.03 \pm 0.01$ \\
\hline \multirow[t]{2}{*}{ FV Apple 2} & $114 \pm 2.9$ & $65 \pm 4.2$ & $1.01 \pm 0.06$ & $0.23 \pm 0.01$ \\
\hline & $172 \pm 82^{a}$ & $54 \pm 16^{a}$ & $0.64 \pm 0.53^{a}$ & $0.13 \pm 0.14$ \\
\hline FV Rose petals & $436 \pm 18.3$ & $247 \pm 14.0$ & $2.46 \pm 0.06$ & $1.51 \pm 0.05$ \\
\hline
\end{tabular}

GAE - gallic acid equivalent, QE - quercetin equivalent, AsA - ascorbic acid, TE - trolox equivalent.

Values were expressed as an average \pm standard deviation (S.D.).

Different letters within the same column indicate significant differences at $p<0.05$ (ANOVA test). 
and FV with rose petals. The amount of TP ranged from $113 \pm 4.6$ (WWCV) to $706 \pm 14.1$ (RWHV 1) mg GAE L $\mathrm{L}^{-1}$. The TP content of RWHVs was not significantly higher than RWCV. On the other hand, significantly higher amounts of TP were observed for WWHV against those of commercial white wine vinegar. Among FVs, rose petal vinegar exhibited significantly the highest TP $\left(436 \pm 18.3 \mathrm{mg} \mathrm{GAE} \mathrm{L}^{-1}\right)$, similar to those of red wine vinegars. Lastly, the red balsamic samples contained a significantly higher TP content than the white balsamic. Despite its wide use, it is important to note that the Folin-Ciocalteu method is potentially affected by several interfering substances such as sulfur dioxide, ascorbic acid, sugar, aromatic amines, proteins, and non-phenolic organic substances that react with the Folin-Ciocalteu reagent (Singleton et al., 1999). The TF content of the 18 examined vinegars ranged between $43 \pm 1.2$ (FV with apple 1) and $2420 \pm 26.5$ (red balsamic vinegar) $\mathrm{mg} \mathrm{QE} \mathrm{L}^{-1}$. The $\mathrm{TF}$ content of the red wine vinegars was between 137 \pm 12.7 (RWHV 5) and $1280 \pm 52.9$ (RWHV 2); whereas the TF content of two white wine vinegars and three FVs ranged up to $262 \pm 13.1$ (WWCV) and $247 \pm 14.0$ (FV with rose petals), respectively. Among the three different examined balsamic vinegar samples, significant differences were observed; the highest amount of TF was determined for the red balsamic vinegar sample $\left(2420 \pm 26.5 \mathrm{mg} \mathrm{QE} \mathrm{L}^{-1}\right)$. The red balsamic's high concentration of flavonoids results from this vinegar's main components and the red grapes, which are rich in flavonoids. Also, the addition of concentrated must and a natural caramel color, which are mentioned in the product label, can increase the already high levels of flavonoids. Lastly, significant differences were found among the fruit vinegars (apple and rose petal vinegar) and homemade and commercial red and white wine vinegars. Our findings are in agreement with those reported by published research works (Karta et al., 2018; Kharchoufi et al., 2018; Sinanoglou et al., 2018).

\section{Antioxidant capacity}

In the present study, the total antioxidant capacity of the vinegar samples was quantified by DPPH and ABTS assays. These results are summarized in Table 2 . Red wine vinegars exhibited the highest antioxidant capacity ranging up to $2.54 \pm 0.05 \mathrm{mM}$ AsA (RWHV 2). This high antioxidant capacity of red wine vinegars and balsamic vinegars can be attributed mainly to their increased total phenol content. Additionally, the antioxidant capacity of red balsamic vinegar and FV with rose petals was found to be $2.15 \pm 0.07$ and $2.46 \pm 0.06 \mathrm{mM}$ AsA, respectively. DPPH values in white wine vinegars ranged up to $1.39 \pm 0.07 \mathrm{mM}$ AsA. Similar trends of results were observed performing ABTS assay.

\section{Correlations}

Correlation analysis of the antioxidative parameters of the analyzed vinegar samples with their polyphenol contents and color parameters was performed (Table 3 ). In the results, a highly positive correlation can be observed between antioxidant capacity and polyphenol composition $(0.4353<r<0.8485 ; p<0.01)$. The total phenol content of the examined vinegars exhibited the strongest correlation with antioxidant properties. Specifically, the correlation between TP and DPPH was 0.8485 , while the correlation among TP and ABTS was 0.6799. In addition, the correlation

Table 3. Correlations between polyphenol content, antioxidant capacities and color parameters

\begin{tabular}{|c|c|c|c|c|c|}
\hline & $\begin{array}{l}\text { Total phenolic } \\
\text { content }\end{array}$ & $\begin{array}{c}\text { Total flavonoid } \\
\text { content }\end{array}$ & DPPH assay & ABTS assay & Color density \\
\hline Total phenolic content & 1 & & & & \\
\hline Total flavonoid content & 0.6593 & 1 & & & \\
\hline DPPH assay & 0.8485 & 0.4454 & 1 & & \\
\hline ABTS assay & 0.6799 & 0.4353 & 0.8676 & 1 & \\
\hline Color density & 0.4758 & 0.8473 & 0.2556 & 0.2508 & 1 \\
\hline
\end{tabular}


between $\mathrm{TF}$ and DPPH, as well as TF and ABTS, are 0.4454 and 0.4353 , respectively. An excellent correlation can also be found between the $\mathrm{TF}$ and $\mathrm{CD}$ $(r=0.8676)$, while a weaker correlation was observed between TP and CD (0.4758), and antioxidant assays and $\mathrm{CD}$ (average: 0.25 ). These results indicated that the antioxidant capacity of the examined vinegars was mainly influenced by their total phenol content, followed by flavonoids and $\mathrm{CD}$ values.

\section{CONCLUSIONS}

The current work presented results about the antioxidant profiles of vinegars made from different raw materials, both of homemade origin and from the Greek market. The results showed that red wine vinegars and red balsamic vinegars had the highest levels of total phenols followed by fruit vinegars, white wine vinegars and white balsamic vinegars. We believe that the obtained data is useful to consumers. Also, these results could be used to extend our knowledge of the composition of vinegars and for the development and optimization of new vinegars based on functional raw materials.

\section{REFERENCES}

Aguiar, A., Nascimento, R. A. A., Ferretti, L. P., Goncalves, A. R. (2005). Determination of organic acids and ethanol in commercial vinegars. Braz. J. Technol., 5, 51-56.

Arnous, A., Makris, D. P., Kefalas, P. (2001). Effect of principal polyphenolic components in relation to antioxidant characteristics of aged red wines. J. Agr. Food Chem., 49, 5736-5742. https://doi.org/10.1021/jf010827s

Arvaniti, O. S., Samaras, Y., Gatidou, G., Thomaidis, N. S., Stasinakis, A. S. (2019). Review on fresh and dried figs: Chemical analysis and occurrence of phytochemical compounds, antioxidant capacity and health effects. Food Res. Int., 119, 244-267. https://doi.org/10.1016/j. foodres.2019.01.055

Barnaba, C., Dellacassa, E., Nicolini, G., Nardin, T., Malacarne, M., Larcher, R. (2015). Identification and quantification of 56 targeted phenols in wines, spirits, and vinegars by online solid-phase extraction-ultrahigh-performance liquid chromatography-quadrupole-orbitrap mass spectrometry. J. Chromatogr. A, 1423, 124-135. https://doi.org/10.1016/j.chroma.2015.10.085
Brand-Williams, W., Cuvelier, M. E., Berset, C. (1995). Use of a free radical method to evaluate antioxidant activity. Food Sci. Technol., 28, 25-30. https://doi.org/10.1016/ S0023-6438(95)80008-5

Budak, H. N., Guzel-Seydim, Z. B. (2010). Antioxidant activity and phenolic content of wine vinegars produced by two different techniques. J Sci. Food Agric., 90, 2021-2026. https://doi.org/10.1002/jsfa.4047

Budak, N. H., Aykin, E., Seydim, A. C., Greene, A. K., Guzel-Seydim, Z. B. (2014). Functional properties of vinegar. J. Food Sci., 79, 757-794. https://doi. org/10.1111/1750-3841.12434

Cruz, M., Correia, A. C., Goncalves, F. J., Jordao, A. M. (2018). Phenolic composition and total antioxidant capacity analysis of red wine vinegars commercialized in Portuguese market. Cienc. Tec. Vitivinic., 33, 102-115. https://doi.org/10.1051/ctv/20183302102

Ho, C. H., Lazim, A. M., Fazry, S., Zaki, U. K. H. H., Lim, S. J. (2017). Varieties, production, composition and health benefits of vinegars: A review. Food Chem., 21, 16211630. https://doi.org/10.1016/j.foodchem.2016.10.128

Karta, I. W., Sundari, C. D. W. H., Susila, L. A. N. K. E., Mastra, N. (2018). Analysis of active content in "Salacca Vinegar" in Sibetan village with potential as antidiabetic and anticancer. Indian J. Public Health Res. Dev., 9, 424-428. https://doi.org/10.5958/09765506.2018.00480.1

Kelebek, H., Kadiroglu, P., Demircan, N. B., Selli, S. (2017). Screening of bioactive components in grape and apple vinegars: Antioxidant and antimicrobial potential. J. I. Brewing, 123, 407-416. https://doi.org/10.1002/jib.432

Kharchoufi, S., Gomez, J., Lasanta, C., Castro, R., Sainz, F., Hamdi, M. (2018). Benchmarking laboratory-scale pomegranate vinegar against commercial wine vinegars: antioxidant activity and chemical composition. J. Sci. Food and Agric., 98, 4749-4758. https://doi.org/doi: 10.1002/jsfa. 9011

Lalou, S., Hatzidimitriou, E., Papadopoulou, M., Kontogianni, V. G., Tsiafoulis, C. D., Gerothanassis, I. P., Tsimidou, M. Z. (2015). Beyond traditional balsamic vinegar: Compositional and sensorial characteristics of industrial balsamic vinegars and regulatory requirements. J. Food Compos. Anal., 43, 175-184. https://doi.org/10.1016/j. jfca.2015.07.001

Ozturk, I., Caliskan, O., Tornuk, F., Ozcan, N., Yalcin, H., Baslar, M., Sagdic, O. (2015). Antioxidant, antimicrobial, mineral, volatile, physicochemical and microbiological characteristics of traditional home-made Turkish vinegars. Food Sci. Technol., 63, 144-151. https://doi. org/10.1016/j.lwt.2015.03.003 
Re, R., Pellegrini, N., Proteggente, A., Pannala, A., Yang, M., Rice-Evans, C. (1999). Antioxidant activity applying an improved ABTS radical cation decolorization assay. Free Radic. Biol. Med., 26, 1231-1237. https://doi. org/10.1016/S0891-5849(98)00315-3

Sanarico, D., Motta, S., Bertolini, L., Antonelli, A. (2003). HPLC determination of organic acids in traditional balsamic vinegar of Reggio Emilia. J. Liq. Chromatogr. Relat. Technol., 26, 2177-2187. https://doi.org/10.1081/ JLC-120022402

Sinanoglou, V. J., Zoumpoulakis, P., Fotakis, C., Kalogeropoulos, N. Sakellari, A., Karavoltsos, S., Strati, I. F. (2018). On the characterization and correlation of compositional, antioxidant and colour profile of common and balsamic vinegars. Antioxidants, 7, 139-146. https://doi.org/10.3390/antiox7100139

Singleton, V. L., Orthofer, R., Lamuela-Raventos, R. M. (1999). Analysis of total phenols and other oxidation substrates and antioxidants by means of Folin-Ciocalteu reagent. Meth. Enzymol., 299, 152-178. https://doi. org/10.1016/S0076-6879(99)99017-1
Ubeda, C., Hidalgo, C., Torija, M. J., Mas, A., Troncoso, A. M., Morales, M. L. (2011). Evaluation of antioxidant activity and total phenols index in persimmon vinegars produced by different processes. Food Sci. Technol., 44, 1591-1596. https://doi.org/10.1016/j.lwt.2011.03.001

Xia, T., Yao, J., Zhang, J., Duan, W., Zhang, B., Xie, X., ..., Wang, M. (2018). Evaluation of nutritional compositions, bioactive compounds, and antioxidant activities of Shanxi aged vinegars during the aging process. J. Food Sci., 83, 2638-2644. https://doi.org/10.1111/17503841.14356

Yu, Y. J., Lu, Z. M., Yu, N. H., Xu, W., Li, G. Q., Shi, J. S., $\mathrm{Xu}, \mathrm{Z}$. H. (2012). HS-SPME/GC-MS and chemometrics for volatile composition of Chinese traditional aromatic vinegar in the Zhenjiang region. J. I. Brewing, 118, 133141. https://doi.org/10.1002/jib.20

Zhishen, J., Mengcheng, T., Jianming, W. (1999). The determination of flavonoid contents in mulberry and their scavenging effects on superoxide radicals. Food Chem., 64, 555-559. https://doi.org/10.1016/S03088146(98)00102-2 